\title{
Floods on alluvial fans: implications for reworking rates, morphology and fan hazards
}

\author{
A. S. Leenman ${ }^{1}$, B. C. Eaton ${ }^{1}$, and L. G. MacKenzie ${ }^{2}$ \\ ${ }^{1}$ Department of Geography, University of British Columbia, Vancouver BC, Canada \\ ${ }^{2}$ Department of Forest Resources Management, University of British Columbia, Vancouver BC, Canada
}

\section{Key Points:}

- Experiments with the same mean flow but different hydrograph shapes generated alluvial fans with different slopes

- Lateral migration and morphologic change increased non-linearly with the flow, so that small changes to hydrograph shape had a meaningful impact on flood response

- A single, constant flow is inappropriate to represent the wide range of flows on natural fans

This manuscript has been submitted to JGR: Earth Surface and has not yet undergone peer-review; subsequent versions of the manuscript may differ. If accepted, this page will be updated with a DOI for the published manuscript.

The data associated with this paper will be published on the Canadian Federated Research Data Repository, at https://doi.org/10.20383/102.0482.

Contact the corresponding author via email at anya.leenman@alumni.ubc.ca, or twitter@AnyaLeenman.

Corresponding author: Anya Leenman, anya.leenman@alumni.ubc.ca 


\begin{abstract}
Flood events are the agents of change on alluvial fans. However, most alluvial fan experiments have used constant flows to model fans and the channels upon them. Here, we present results from a series of alluvial fan experiments with different patterns of flow variation (i.e. different hydrograph shapes). We conducted experiments with 1) constant flow, 2) alternating high and low flows, 3) a moderate flood peak that decayed slowly, alternating with a constant low flow, and 4) a high flood peak that decayed rapidly, alternating with a constant low flow. Importantly, all experiments had the same mean flow and sediment supply, but the different hydrographs generated fans with different slopes. In addition, higher peak flows led to increased lateral migration rates and increased erosion and deposition. These results challenge the notion that a single representative flow can be used to approximate the geomorphic effects of a range of flows in a natural stream. Moreover, the data suggest that hydrograph shape can govern the geomorphic impact of a flood event. Our findings indicate how altered basin hydrology (for instance, through changes to land cover) could influence geomorphic change and natural hazards on alluvial fans.
\end{abstract}

\title{
Plain Language Summary
}

The steep streams that flow down alluvial fans experience a wide range of high and low flows. Here, we use a series of experiments with a small-scale model of a fan to explore the importance of this flow variability. We show how the type of flow variability influences hazards such as stream bank erosion, or the rapid inundation of areas that were previously dry. Our results suggest that when high flows occur in these steep streams, their magnitude and duration control their impact on the stream channel. Anything that changes the magnitude and duration of high flows (for instance, a change to the landscape upstream) could alter the severity of future flood events.

\section{Introduction}

Flood events drive change on alluvial fans. Although morphologic change is not negligible in the periods of low or moderate flow between floods, when 'secondary processes' dominate (Blair \& McPherson, 1994; Vincent, 2020), it is high-flow events that tend to drastically rework fan morphology by reshaping or redirecting channels - often with catastrophic consequences for people or infrastructure on those fans (Beaumont \& Oberlander, 1971; Church \& Jakob, 2020; Field, 2001; Gutiérrez et al., 1998; Jakob et al., 2016, 2017; Larsen et al., 2001; Pearthree et al., 2004; Santo et al., 2015; Yumuang, 2006). In addition to reworking fan morphology, flood events and other 'primary processes' transport large volumes of sediment onto fans. As a result, flood events with high sediment concentration are one of the main processes that build up alluvial fans.

'Flood' carries alternative meanings across different contexts and applications. In this paper, we consider flood 'events' - that is, a sudden and short-term increase in flow above a background value. We are interested in flow variability over a reasonably short time: what is the effect of a rapid increase in flow, and of the shape of the flood hydrograph? Consequently, when we refer to high flows or flood events, we are not referring to a particular flood magnitude or recurrence interval. Rather, we are referring to the temporary increase in flow typically triggered by a heavy rainfall event. The morphologic effects of such temporal flow variation are the focus of this paper. In modeling variable flow, we also investigate the effects of not including flow variability in alluvial fan models and simulations; that is, we evaluate the morphologic impact of different scales of temporal averaging in the hydrological input.

Despite the importance of variable flow in shaping fans, experimental models of alluvial fans have generally used constant flow (Clarke et al., 2010; Van Dijk et al., 2012; 
Schumm et al., 1987; Whipple et al., 1998; Reitz \& Jerolmack, 2012; Reitz et al., 2010). This practice rests upon the assumption that a 'representative' flow rate can be used to approximate the range of flows that occur in a stream. These constant flow experiments have provided a nuanced and invaluable understanding of autogenic dynamics on alluvial fans. Nevertheless, a constant flow represents an environmental scenario that is unlikely in natural streams. Although the practice of using a single constant flow is common, it is not entirely clear how much information is lost by substituting a single flow for a range of flows; that is, how this practice might cause over- or under-estimation of geomorphic process rates in natural systems.

Conceptual work and statistical modeling have suggested that a single flow rate (discharge) may not accurately represent the dynamics of the full range of flows. For instance, Eaton (2013) noted that different aspects of river morphology (e.g. the banks or the bed surface) may be shaped by floods of different frequencies, so that there are likely multiple 'formative' discharges for a given channel. Similarly, Church and Ferguson (2015) emphasized that it is difficult to define a single flow that (over time) creates the same morphology and sedimentology as a range of natural flows, because different processes or morphologic features have different (and non-linear) relations with discharge. The utility of the 'formative' flow was further eroded in statistical modeling by S. L. Davidson and Eaton (2018), who compared a traditional regime model of channel geometry (with constant flow) to a stochastic model with variable flood sizes. They showed that, as the variability of flood sizes increased, the channel geometry became more different from that produced by a single discharge in the regime model. Collectively, these works highlight the difficulty of selecting a single flow as representative. Moreover, they highlight some biases which may arise from the temporal averaging of a range of flows to give a single representative flow.

In the past five years, experiments have demonstrated that variable flow affects the morphology and evolution of fan-deltas. For instance, an experiment by Ganti et al. (2016) with variable flow produced fan-delta morphology and avulsion dynamics that differed from their experiment with constant flow. Miller et al. (2019) compared experiments with variable flow to a constant 'flood' flow, and found that variable flow favored the construction of larger deltas with faster progradation rates. Moreover, experiments by Piliouras et al. (2017) showed that on vegetated fan-deltas, variable flow generated fan-deltas with different morphology and vegetation growth patterns, and altered flow-vegetation interactions. Collectively, these experiments highlight how, at least on fan-deltas, using variable flow not only affects morphology, but also the dynamics of channels and of natural hazards such as avulsion.

In light of the experimental evidence and issues described above, we evaluate the distortions introduced through different scales of temporal averaging in the flow to alluvial fans. We present data from four fan experiments with differing scales of flow variability. Run 1 had a constant flow, while Run 2 had alternating high and low flow. Runs 3-4 had repeated 'flood events' with very steep rising limbs, decaying falling limbs, and a period of constant low flow before the next high-flow event. We collected topographic and photographic data at high spatial $(1 \mathrm{~mm})$ and temporal (1-minute) resolution.

Using these data, we investigate the influence of delivering the same volume of water through different hydrograph shapes. We quantify the impact of the hydrographs by examining their effects on fan gradient, lateral channel migration, and vertical geomorphic activity (i.e. erosion and deposition). We compare these results to our experiment with constant flow, in order to investigate the effects of averaging out flow variability. We reflect on the implications of our research for flood hazard management on natural fans and for notions of representative discharge. Lastly, we consider the implications of our findings for stream responses to environmental change. 


\section{Methods}

\subsection{Model set-up}

We conducted four experiments with a physical model of a generic gravel-cobble alluvial fan. The experiments were run in a stream table at the University of British Columbia's Biogeomorphology Experimental Laboratory. The stream table measured $2.44 \times 2.44$ $\times 0.3 \mathrm{~m}$ (Figure 1), and we attached a $0.2 \times 0.5 \times 0.3 \mathrm{~m}$ feeder channel at one corner. We delivered water from a constant head tank, or from a variable head tank (monitored by a pressure sensor) for the runs with decaying flood peaks. A sediment feeder delivered sediment via a rotating pipe; the feed rate was set by the inclination of the pipe. Sediment and water inputs were mixed in a funnel and then dropped into the experiment at the head of the feeder channel. We allowed sediment to aggrade and degrade freely in the feeder channel, to mimic sediment supply buffering in a bedrock confined reach upstream of a natural fan.

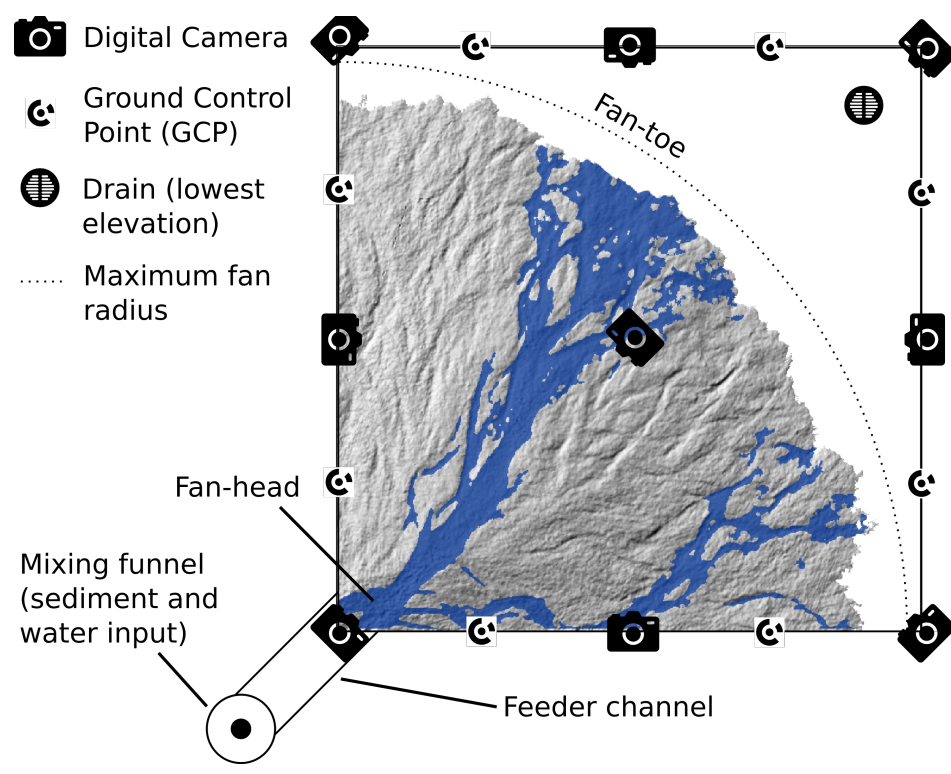

Figure 1. Experimental setup (not to scale). Water and sediment were mixed in the funnel and dropped into the head of the feeder channel, where sediment could aggrade and degrade. The hillshaded topography and flow map example are from Run 1 repeat 1 at 19 hours, 9 minutes.

We set the stream table slope to $0.0002 \mathrm{~m} \mathrm{~m}^{-1}(0.02 \%)$ to generate flow across the table to the drain. To roughen the boundary, we glued $2 \mathrm{~mm}$ sand grains and Lego sheets to the base and walls of the table. We dyed the water in the experiment blue, in order to apply image analysis techniques to automatically map the flow from photographs.

We collected data using an adaptation of Structure-from-Motion photogrammetry. The data collection system and its spatial accuracy are described in detail in Leenman and Eaton (2021) and Leenman (2021); here we give a brief summary. We mounted nine digital single-lens reflex cameras above the stream table to 'view' the experiment from different angles (Figure 1). All cameras captured photos synchronously; in the experiments with flood events, the first photo was always $\sim 30$ seconds after the start of the flood (see Figure 2). We glued eight 'ground control points' (GCPs) to the table walls, allowing us to georeference the photos to a local coordinate system. Each set of nine photos was processed in "AgiSoft PhotoScan Professional" (2018) to generate a topographic point cloud $\left(\sim 280,000\right.$ points per $\left.\mathrm{m}^{2}\right)$ and co-registered orthophoto (1 $\mathrm{mm}$ resolution). 


\subsection{Experimental Scenarios}

We conducted four experimental runs, each with different flow conditions. Run 1 had constant flow; Runs 2-4 had periodic flood events. Each flood event lasted 5 minutes and was followed by a 5 -minute low-flow period. We repeated this ten-minute highto-low flow cycle for the whole experiment.

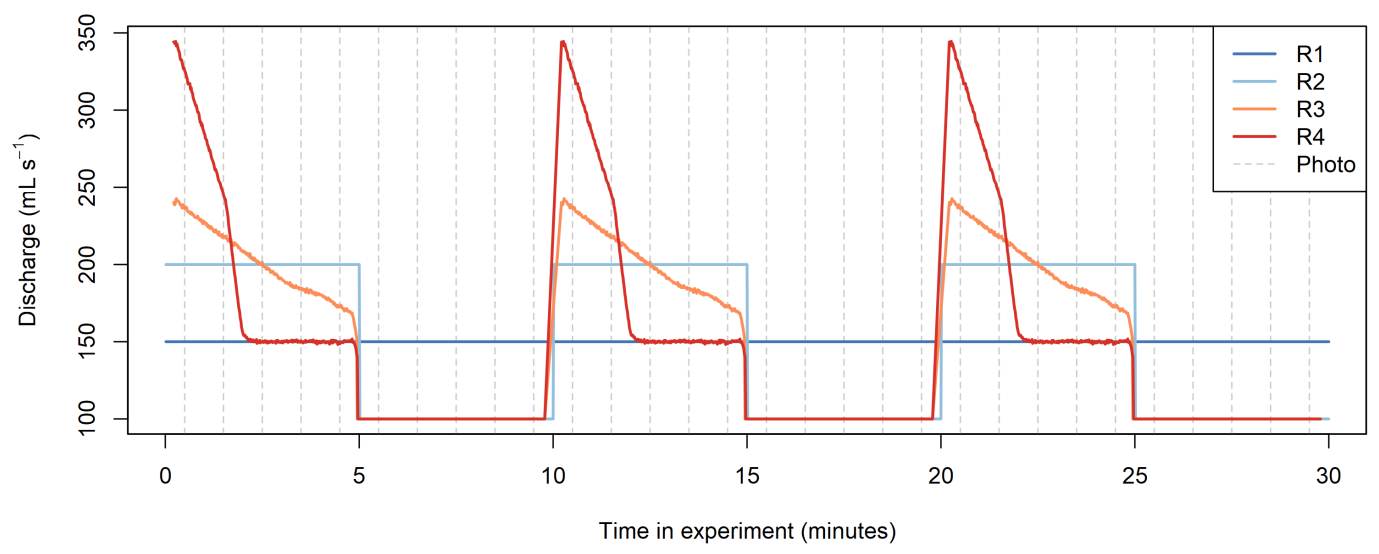

Figure 2. Flow rates for each experiment. The mean flow and the total water input in the ten-minute cycle was the same in all experiments.

The hydrographs for each experiment are shown in Figure 2. Run 2 had 'flat' flood hydrographs, with a constant flood flow of $200 \mathrm{~mL} \mathrm{~s}^{-1}$. Run 3 had a low flood peak of $\sim 240 \mathrm{~mL} \mathrm{~s}^{-1}$, that decayed slowly. Run 4 had a high flood peak of $\sim 340 \mathrm{~mL} \mathrm{~s}^{-1}$, that decayed rapidly. All variable flow experiments (Runs 2-4) had a constant low flow of 100 $\mathrm{mL} \mathrm{s}{ }^{-1}$ for five minutes between the flood events.

One of our aims was to investigate the impact of temporally averaging flow to the fan. We therefore designed the experiments so that in Run 1, all flow variability was averaged out to produce a constant flow of $150 \mathrm{~mL} \mathrm{~s}^{-1}$, equal to the mean flow in Runs 24. The total volume of water delivered in each ten-minute period (the high-to-low flow cycle) was therefore equal across all four experiments. Moreover, in Runs 2-4, each flood peak contained the same volume of water, but with a different temporal distribution in the different experiments. We also tested the impact of averaging the flow within a flood event: in Run 2, we averaged out the decaying flood hydrographs of Runs 3 and 4, instead using a constant flood flow that was equal to the mean flood-event flow in Runs 3 and 4 .

In all experiments, the sediment supply to the feeder channel was constant at $5 \mathrm{~g}$ $\mathrm{s}^{-1}$. Sediment concentration, then, was determined by the flow variations. Because we allowed sediment to aggrade and degrade freely in the feeder channel, the effective sediment feed rate (and sediment concentration) could readily adjust in response to flow variation, through cutting or filling of the sediment stored in the feeder channel. This process was designed to mimic the behavior of the steep, narrow streams that typically feed alluvial fans.

Our sediment mixture was widely graded. Using a length scale of 1:128, we approximated the experimental grain size distribution (GSD) from a surface gravel sample collected on Three-Sisters Creek fan, Canmore, Canada. The experimental GSD ranged from $0.25 \mathrm{~mm}$ to $8 \mathrm{~mm}$, and $95 \%$ of the mixture was finer than $2.3 \mathrm{~mm}$ (Figure 3). Subsurface flow through the sandy mixture allowed seepage channels to form, which have been 
observed on natural fans; for instance, phenomena such as downfan channel narrowing and spring formation have been attributed to infiltration on fans (S. K. Davidson et al., 2013; Kesel \& Lowe, 1987; Woods et al., 2006).

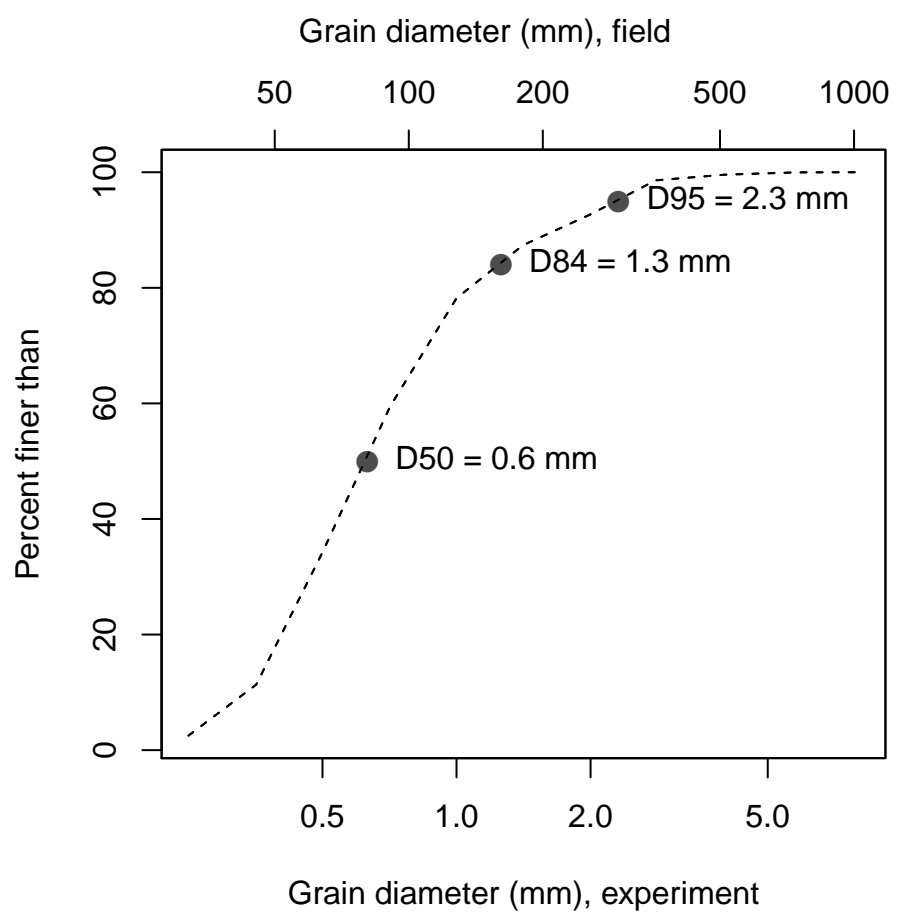

Figure 3. The grain size distribution (GSD) of our experimental sediment mixture.

We ran each experiment for $\sim 20$ hours, until the fan prograded to the stream table edges. For each experiment, we then ran two additional repeats. Unless otherwise stated, our figures show data from all three repeats of the experiment(s).

\subsection{Experimental Approach}

Our experimental fan is a 'similarity-of-process' model or 'analog' model (c.f. Hooke (1968a); Paola et al. (2009)), as are most physical models of alluvial fans and fan-deltas (Bryant et al., 1995; Clarke et al., 2010; Davies \& Korup, 2007; Van Dijk et al., 2009; De Haas et al., 2016, 2018; Hamilton et al., 2013; Hooke, 1967, 1968b; Hooke \& Rohrer, 1979; Miller et al., 2019; Piliouras et al., 2017; Reitz \& Jerolmack, 2012; Schumm et al., 1987). In our model, flow reshapes the fan through the erosion, transport and deposition of sediment, thereby incorporating the key formative processes on natural fans. Because we use the 'similarity-of-process' approach, we do not attempt to extrapolate the rates or volumes of our findings to the field. Instead, comparisons between our different experiments demonstrate how natural fans are likely to respond to different scales of flow variability. Such comparisons also highlight the distortions introduced through the flow averaging we impose in Runs 1 and 2.

In alluvial fan models, it is difficult to meet the Froude scaling requirements described by Peakall et al. (1996) due to the large geometric scaling ratio required to build a conveniently small laboratory fan. In our experiments it was not possible to even control the Froude $(F r)$ or Reynolds $(R e)$ numbers, as the fan's slope and channel dimen- 


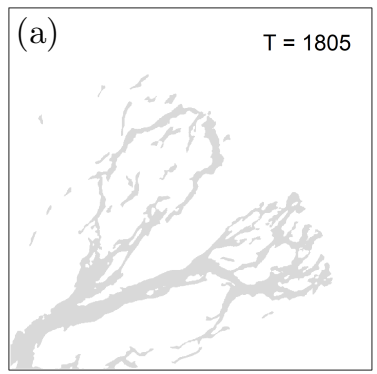
ics that are of interest to us. face.

sions were self-formed. We have estimated these parameters for the fan-head (where flow was generally confined to a single channel), based on estimated flow width, depth and velocity. Estimated $F r$ was 1.5-2.9, depending on the flow. These supercritical values match observations during floods on natural fans (Beaumont \& Oberlander, 1971; Rahn, 1967). Farther downfan, flow likely became subcritical as it spread into multiple distributaries. Using the $D_{84}$ as a representative grain size, we estimated particle Reynolds numbers $\left(R e^{*}\right)$ of $60-80$ (depending on the flow), which conform to the threshold of 15 proposed by Parker (1979) and Ashworth et al. (1994), and also conform to the minimum of 70 recommended by Schlichting and Gersten (2016) and Yalin (1971) for some flows. We estimated $R e$ of 760-2,600, indicating that flow was generally in the transitional regime between laminar and turbulent flow (preventing the attainment of Froude similarity). Many other experimental studies of fans have also reported flows that were transitional or not fully turbulent (Davies et al., 2003; Davies \& Korup, 2007; Delorme et al., 2017, 2018; Van Dijk et al., 2012; Guerit et al., 2014; Hamilton et al., 2013; Reitz et al., 2010; Reitz \& Jerolmack, 2012; Whipple et al., 1998). Although these models operate outside of Froude similarity, they were found to successfully reproduce the fan-channel dynam-

\subsection{Data Processing and Analysis}

Our photogrammetric data collection system generated a topographic point cloud and $1 \mathrm{~mm}$ resolution orthophoto for each minute of the experiments. These two data products formed the basis for all subsequent analysis, which was conducted in R ( $\mathrm{R}$ Core Team, 2021) with extensive use of the Raster package (Hijmans, 2020). All analyses were limited to areas of the fan that had aggraded to $>6 \mathrm{~mm}$ above the initial empty table sur-

To analyze the orthophotos, we applied a color filter to map the flow pattern (water was dyed blue in the experiments; see Supplementary Information (SI) for further detail on the flow map generation). We performed change detection between the flow maps (Figure 4), to measure rates of lateral migration and quantify the area affected by avulsions. Specifically, we measured the area newly inundated in each minute, and expressed it as a percentage of fan area at time $(t)$, as follows:

$$
F_{n}(t)=\frac{\text { Area newly inundated in previous minute }(t)}{\text { Fan area }(t)} * 100
$$
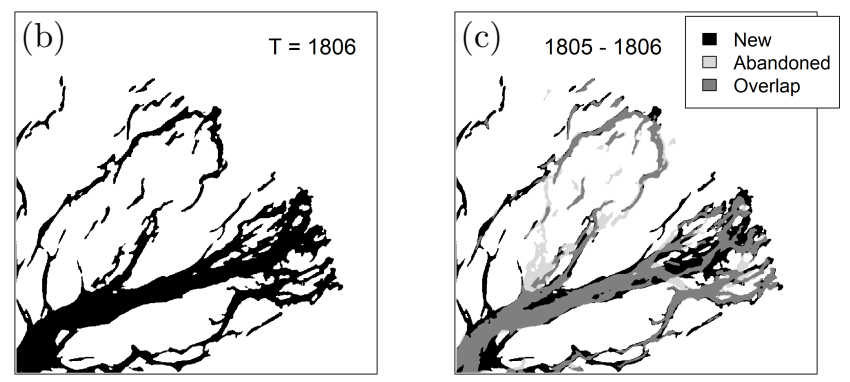

Figure 4. Change detection between successive flow maps. Panels show the flow pattern at 1805 (a) and a minute later at 1806 (b) and then the change detection between them (c). Areas shaded black in (c) correspond to the 'Area newly inundated' in equation 1. Data are from Run 3 repeat 1 . 
To analyze the topographic data, we generated $1 \mathrm{~mm}$ resolution digital elevation models (DEMs) from the point clouds using nearest neighbor interpolation. The DEMs allowed us to quantify fan gradient: for every DEM, we extracted 88 radial downfan profiles, and measured gradient as the slope of a linear regression (profiles were quasi-linear) of elevation against distance from the fan-head.

We also subtracted successive DEMs to generate 'DEMs of Difference' (DoDs); we first smoothed the DEMs with a $7 \times 7 \mathrm{~mm}$ moving average filter. The DoDs allowed us to quantify the volume of erosion and deposition that occurred between each DEM. Erosion or deposition of $<2 \mathrm{~mm}$ was discounted as noise, and removed from all DoDs. We then summed the erosion or deposition across each DoD, to provide a total volume of erosion $\left(V_{e}\right)$ or deposition $\left(V_{d}\right)$ for that minute of the experiment. Finally, we summed the absolute values of $V_{e}$ and $V_{d}$ to give a metric for the total volume of morphologic change $(M)$ in each minute:

$$
M(t)=\left|V_{e}(t)\right|+\left|V_{d}(t)\right|
$$

The DoDs occasionally produced unreasonably large values of $M$. These outliers were identified visually by plotting $M$ against the time in each high-to-low flow cycle (as in Figure 9 in our results). Based on this inspection, we set an outlier-removal threshold for each run and applied it to all repeats of that experiment.

Summing $M$ across each DoD did not allow us to explore spatial patterns of topographic change. In order to explore these spatial patterns in the flood events and lowflow periods of Runs 2-4, we generated five-minute DoDs (again first smoothing with a $7 \times 7 \mathrm{~mm}$ moving window) by subtracting the first and last DEM in each (e.g. $t 5-t 0$ for flood events, and $t 10-t 5$ for low-flows). We then extracted seven equally-spaced downfan profiles from each five-minute DoD. These profiles allowed us to explore how the downfan distribution of erosion and deposition was different in flood events and the intervening low-flow periods.

In this paper, we present and analyze all data from 12 hours of experimental running time and onward. Following Leenman and Eaton (2021), we exclude data from earlier in the experiments, as fan morphology and dynamics appeared to be scale dependent prior to this cutoff.

\section{Results}

To gain a general understanding of how our experiments behaved, we encourage readers to view the experimental time-lapse videos: https://youtu.be/ML2LV28MQEM (Run 1), https://youtu.be/_OwWnb39PYE (Run 2), https://youtu.be/NxVGxepg4BQ (Run 3), and https://youtu.be/1ua_whH9jME (Run 4). Additional, high-frequency time-lapses were also generated for Run 3 (https://youtu.be/L-27xGWe0Cw) and Run 4 (https://youtu.be/NY5E_jxee2E).

Flow on the fans was highly dynamic; channels formed and re-formed in just a few minutes, and avulsion was frequent. The flow pattern was almost always multi-threaded. For the runs with floods, the start of the flood peak typically increased the fraction of the fan covered by flow. The areal extent of inundation was larger when the flood peak was larger (Figure 5, upper panel). Often, this inundation also rearranged flow patterns (i.e. triggered avulsion). Later in each flood event, channels adjusted through rapid lateral migration. When flow dropped to $100 \mathrm{~mL} \mathrm{~s}^{-1}$ in the low-flow periods, flow at first occupied the channel pattern set by the previous flood event (Figure 5, lower panel). Channel pattern then adjusted throughout the low-flow period, via slower lateral migration. 


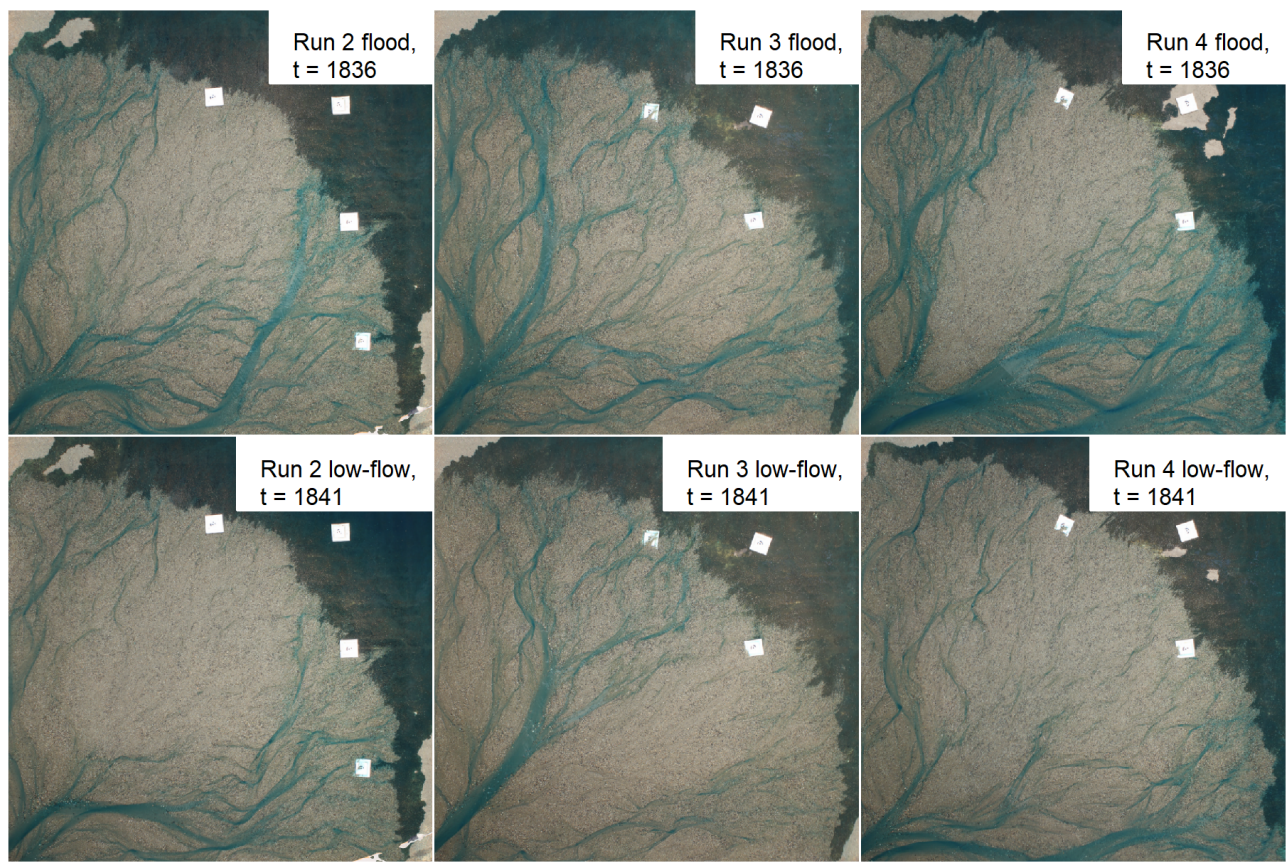

Figure 5. Examples of fan inundation at the beginning of a flood event (upper panel) and the beginning of the following low flow period (lower panel). The flood peak flow increases from left to right. Data are from Run 2 repeat 3, Run 3 repeat 1 and Run 4 repeat 2.

\subsection{Fan gradient}

Fan gradient is a useful metric for how the different flow series affected fan morphology. These data are shown in Figure 6: panel (a) shows an example of the raw data for a single run (Run 1), while (b) shows how median fan gradient varied across the four runs. The decaying hydrographs of Runs 3 and 4 generated fans with the lowest gradients. In Run 2 (with flat hydrographs of the same volume as Runs 3 and 4), fan gradient was steepest. In Run 1 (when the flow variation of Runs 2-4 was replaced by the constant mean flow), fan gradient was intermediate between the two previous cases. Pairwise t-tests show that median gradients for all runs were significantly different, except for Runs 3 and 4; see Table S1 (SI) for further detail on the t-tests and some problems with the assumption of independence for the fan slope data.

\subsection{Lateral (planform) change}

The different hydrographs also influenced lateral channel mobility; we explored this effect by comparing successive flow maps. This change detection allowed us to quantify $F_{n}$, the percentage of the fan newly inundated each minute (Equation 1$) . F_{n}$ is a proxy for the lateral migration rate; high values of $F_{n}$ can represent avulsion. Figure 7 shows the temporal changes in $F_{n}$ : panel (a) gives an example of raw data from Run 4 repeat 2, while panel (b) superimposes all high-to-low flow cycles for each run to demonstrate the general patterns in $F_{n}$.

Lateral mobility rose sharply at the beginning of each flood event; as the peak flow increased from Run 2-4, so did the peak mobility (Figure 7). Given that high values of $F_{n}$ can represent avulsion, this increase in the $F_{n}$ maximum across Runs 2-4 suggests that any avulsions became larger as the peak flow increased. After the initial peak, lateral mobility decreased throughout the flood hydrographs. $F_{n}$ was at a minimum in the 

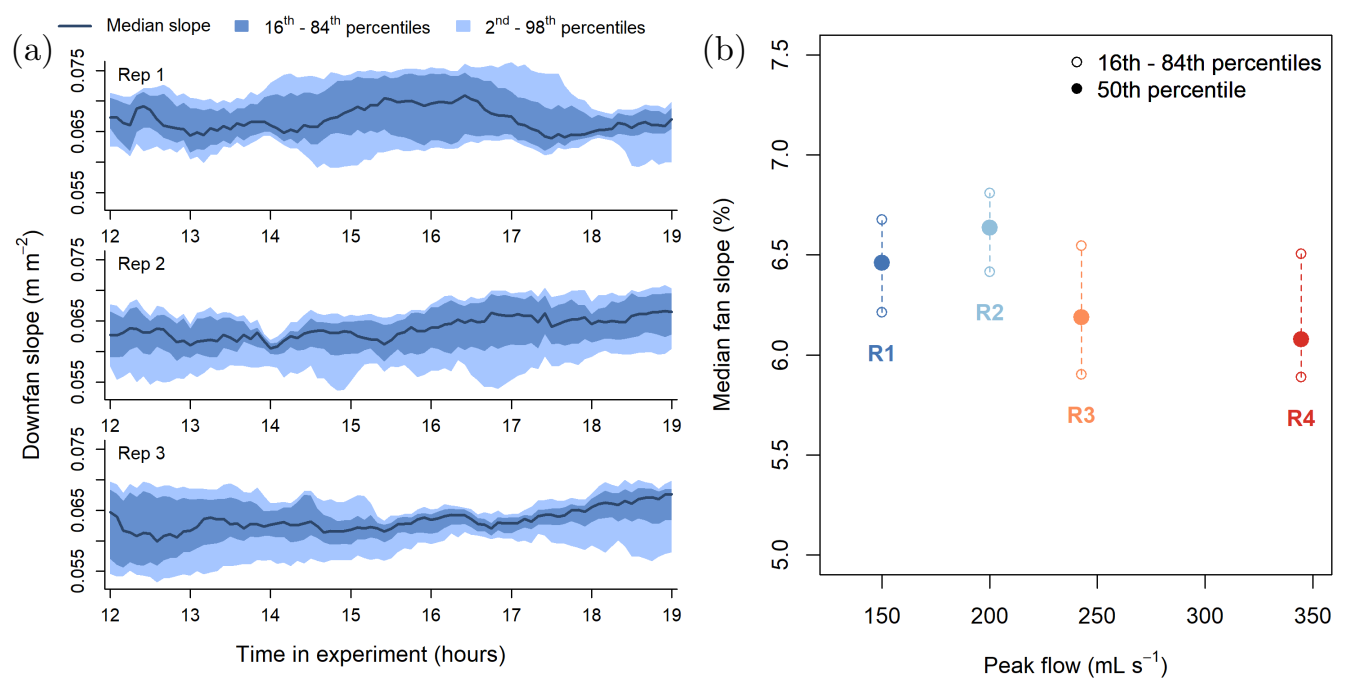

Figure 6. (a) Fan gradient variance in Run 1, from 88 downfan profiles for each minute. The three subplots show data for each repeat. (b) The distribution of median fan slope, from the population of median fan slopes across all three experimental repeats (i.e. data in $\mathrm{R} 1$ distribution taken from thick blue lines in (a)). Data were sampled from 12-19 hours at 15-minute intervals across all experimental repeats. Median fan slope was steeper for Run 2 than Run 1, but less steep for Runs 3 and 4.

first minute of the low-flow, when flow had reduced rapidly and was underfit for the channel formed by the preceding flood. The channel pattern then adjusted to the lower flow through slower lateral migration.

The $F_{n}$ patterns in Figure 7 are similar to the hydrograph shapes. We therefore explored this relation between lateral mobility and flow in Figure 8. This figure shows that, as the maximum flow per minute (a proxy for the instantaneous flow) increased, $F_{n}$ increased faster than linearly. For each experiment, the maximum $F_{n}$ seems to be set by the peak flow, and the fastest reduction in $F_{n}$ with flow rate is between the maximum and second-largest flow measurement. This rapid decay confirms that flood events had their largest impact on planform channel morphology in the first minute of the flood. The non-linear relation between flow and $F_{n}$ in Figure 8 suggests that the temporal distribution of water in a flood hydrograph governs the type of channel response to the flood event. If a flood of a given volume is delivered as a flatter hydrograph (as in Run 2), the potential avulsion size at the start of that flood peak, and lateral migration rates throughout, are likely to be considerably different to a flood where the same volume of water is released as a larger peak that decays more rapidly. 
(a)
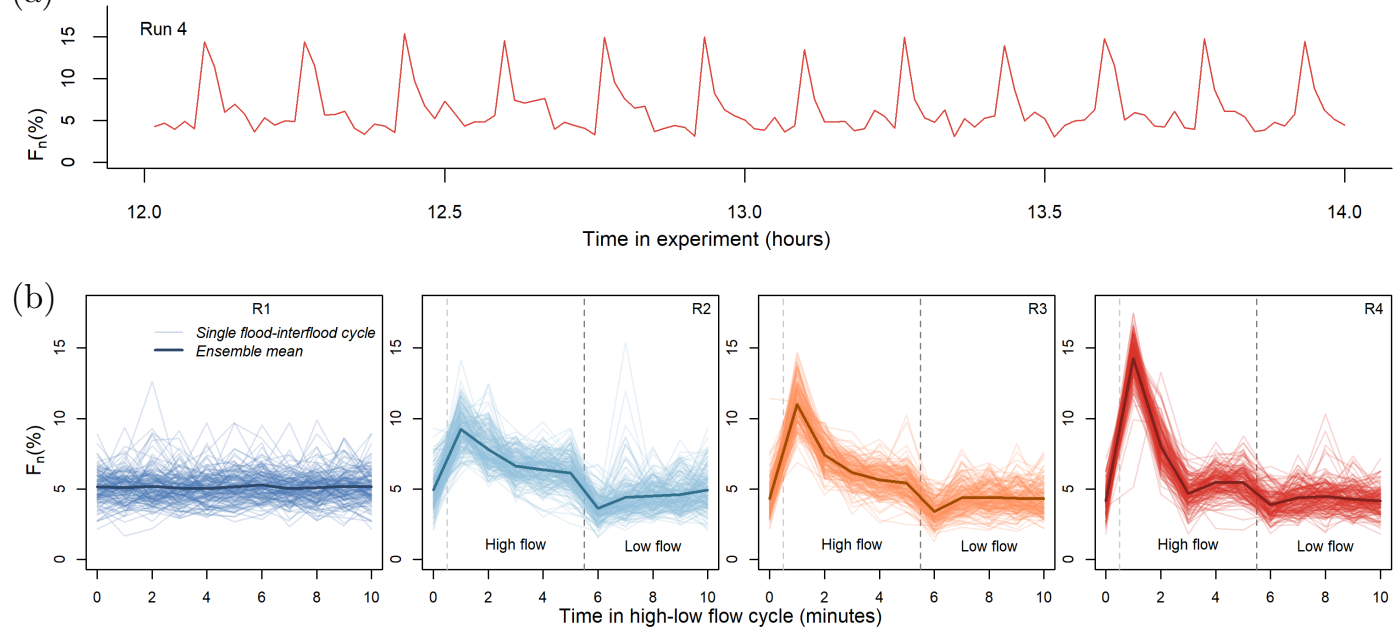

Figure 7. Temporal change in $F_{n}$, the percentage of the fan newly inundated each minute. (a) An example of the change in $F_{n}$ during Run 4 repeat 2 (over 12 high-to-low flow cycles, starting with a low-flow). (b) Each cycle is overlaid, to show the general pattern of $F_{n}$ during the ten-minute high-to-low flow cycle. The dashed line marks the boundary between flood events and low-flow periods.

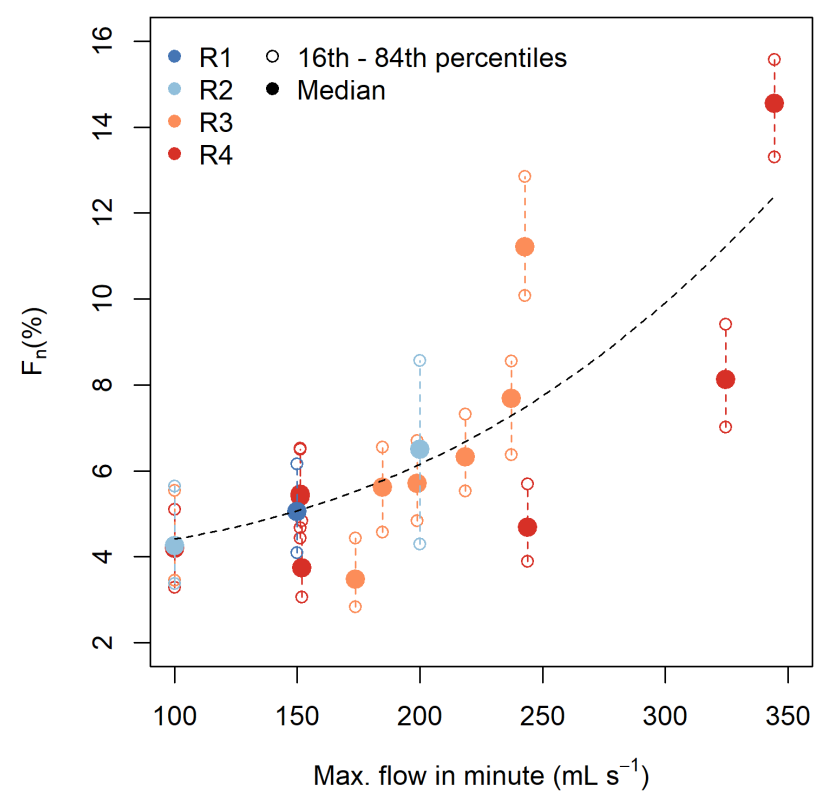

Figure 8. Relationship between $F_{n}$, the percentage of the surface newly inundated, and the maximum flow in any given minute. The black dashed line marks a power-law fitted to the raw data underlying the distributions shown here. See Table S2 (SI) for information on the model fit. 


\subsection{Vertical (morphologic) change}

Given the strong link between flow rates and lateral mobility (Figure 8), we also examined the relation between flow and morphologic change. The DoDs allowed us to quantify morphologic change $M$ as the sum of absolute erosion and deposition volumes in each minute (Equation 2). Figure 9 demonstrates how $M$ varied over the ten-minute high-to-low flow cycle: panel (a) shows raw data from Run 4 repeat 2, while panel (b) superimposes all high-to-low flow cycles for each run to demonstrate the general temporal patterns in morphologic change.

(a)

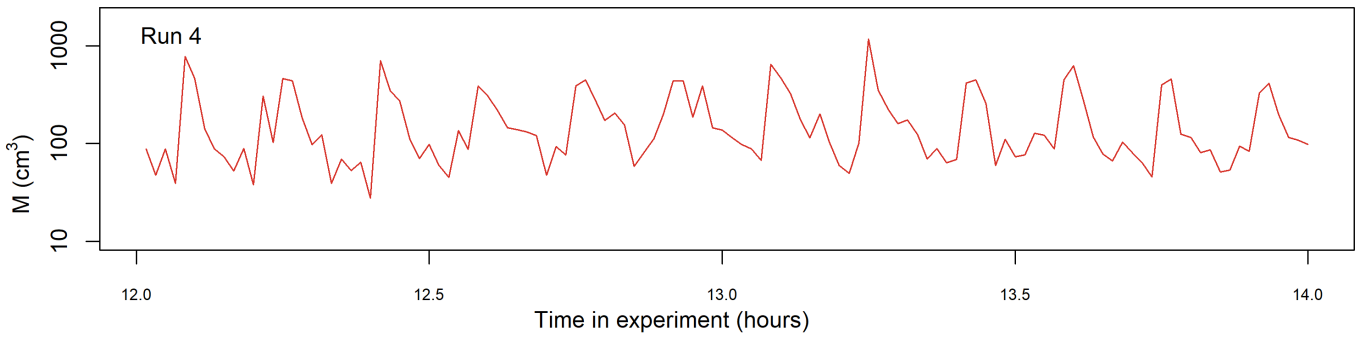

(b)
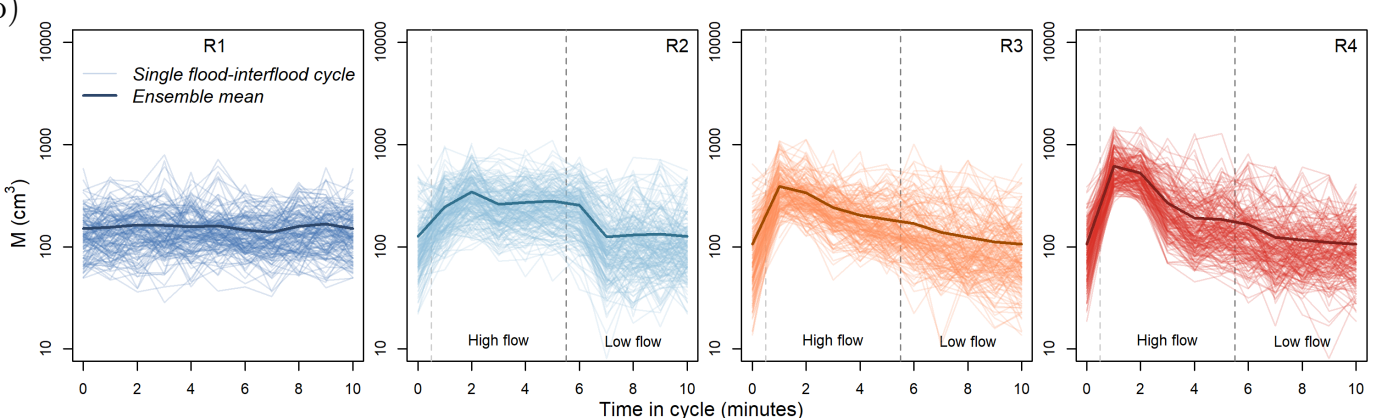

Figure 9. Temporal patterns in minute-to-minute morphologic change $(M)$. Note the y-axis log scale. (a): Sample data from Run 4, showing morphologic change over 12 high-to-low flow cycles (starting with low-flow). (b) All cycles are superimposed, to show the general trend in morphologic change during the high-to-low flow cycle. The bold line shows the mean of all cycles. Data from $\mathrm{t}=12 \mathrm{hrs}$ and onward.

As with $F_{n}$, flood hydrograph shape also controlled the temporal pattern of morphologic change (Figure 9). Generally, morphologic change peaked with the flood peak, as a wave of new material was transported onto the fan-head from the feeder channel. Morphologic change was also high in the second minute of each high-flow period, due to reworking and onward transport of this 'new' sediment brought onto the fan in the preceding minute. In Run 2, reworking during the second minute even raised $M$ to the maximum for that experiment.

We summed $M$ over each ten-minute high-to-low flow cycle to produce Figure 10. This figure implies that increasing the flood peak flow also increased the cumulative morphologic change across the whole ten-minute high-to-low flow cycle; $M_{C 10}$ was lowest for Run 1, with the lowest peak flow, and highest for Run 4. Most morphologic change occurred during the flood events (Figure S1, SI). The exact nature of the relation between peak flow and $M_{C 10}$ is unclear; one repeat of Run 2 was very active, so that $M_{C 10}$ for Run 2 and 3 were not significantly different. Nevertheless, because erosion and deposition volumes provide minimum and maximum estimates of sediment transport in our experiment, $M_{C 10}$ is a useful measure of the geomorphic activity induced by each hydro- 
graph. Figure 10 therefore highlights how constant flow dampened geomorphic activity and variable flow enhanced it, even though the same water volume dispersed across the fan in each ten-minute flow cycle.

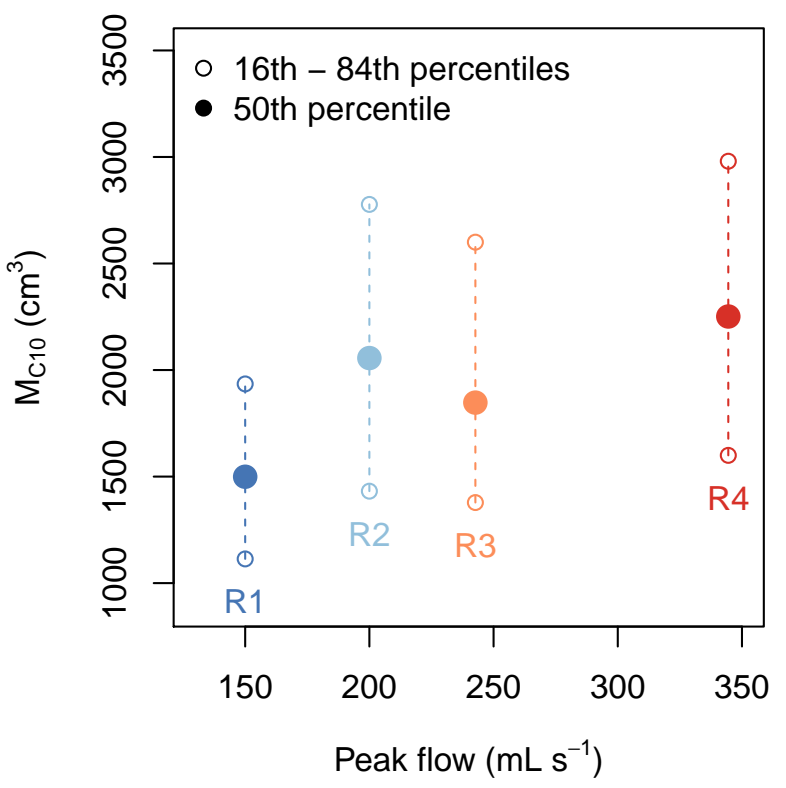

Figure 10. Cumulative morphologic change over the ten-minute high-to-low flow cycles $\left(M_{C 10}\right)$. Cumulative change varied with hydrograph shape; it was smallest with constant flow (R1) and greatest with high flood peaks (R4). Runs 2 and 3 were not significantly different; see Table S3 (SI) for $p$-values.

To further investigate the influence of flow on morphologic change, in Figure 11 we compared the maximum flow at each minute in the high-to-low flow cycle to $M$ in that minute. The figure shows that across all experimental runs, as the flow increased, the associated morphologic change volume increased faster than linearly. This non-linear relation indicates that the temporal distribution of water during a flood event is a crucial control on the volumes of material eroded, transported and deposited on the fan.

Finally, we examined the spatial distribution of morphologic change using downfan profiles extracted from five-minute DoDs that spanned either flood events or low-flow periods (Figure 12). Across all runs, morphologic change was greatest at the fan-head. Figure 12 shows that during flood events, erosion dominated at the fan-head, while deposition was fairly evenly distributed down the fan with a low peak just below the fanhead. Conversely, the low-flow periods resulted in a zone of concentrated deposition at the fan-head, while erosion peaked slightly downstream. The magnitude of fan-head change increased as the flood peak increased from Run 2-4. As with the preceding figures, these data highlight how the geomorphic activity on the fan intensified as the flood peak flow increased, even though the same water volume dispersed across the fan in all flood events. 


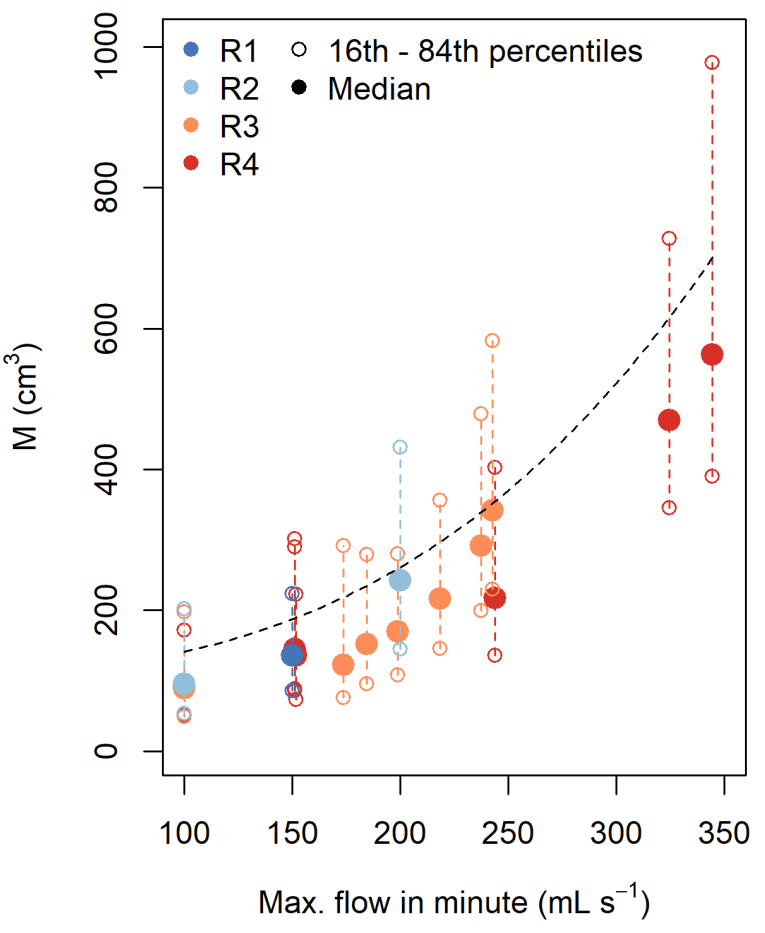

Figure 11. Relationship between the volume of morphologic change $(M)$ in a minute, and the maximum flow in a minute. The black dashed line marks a power-law fitted to the raw data underlying the distributions shown here; most distributions were positively-skewed, causing the relation to plot higher than the medians. See Table S5 (SI) for information on model fit.
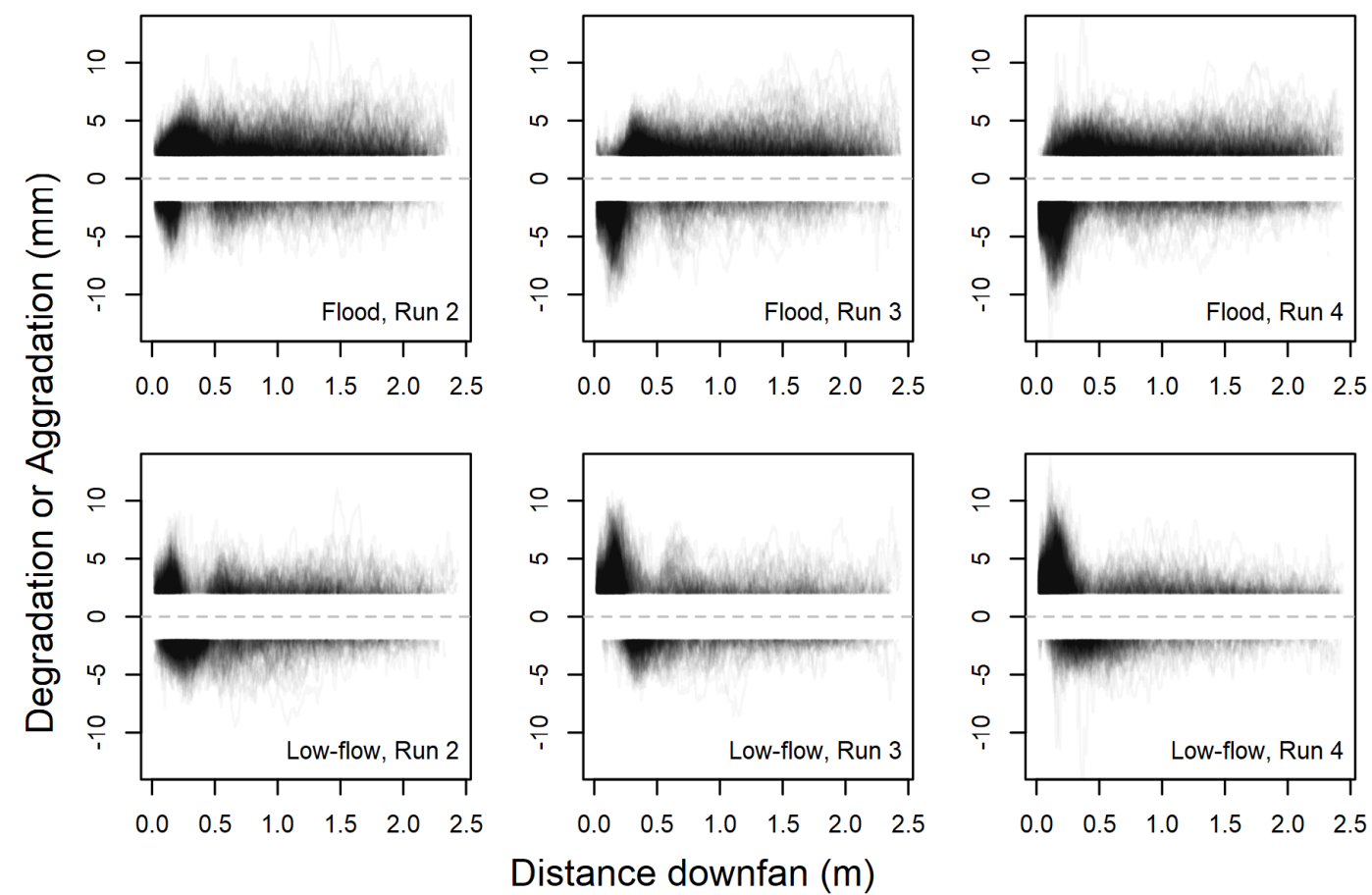

Figure 12. The downfan pattern of deposition and erosion, during floods (above) and lowflows (below). Seven equally-spaced downfan profiles were extracted from the five-minute DoD spanning each flood event or low-flow period. Morphologic change of $<2 \mathrm{~mm}$ was discarded. 


\section{Discussion}

\subsection{Key findings and unresolved questions}

Our experiments exhibited a distinct non-linear relation between the flow rate and our two measures of geomorphic activity: $F_{n}$ (a proxy for lateral mobility), and $M$ (summing vertical morphologic change). As the flow increased, $F_{n}$ and $M$ increased faster than linearly (Figures 8 and 11). This non-linearity explains key differences between our experiments, and particularly the increase in cumulative morphologic change $\left(M_{C 10}\right)$ as peak flow increased from Run 1-4 (Figure 10). Although the exact nature of the relation in Figure 10 is unclear, the non-linear influence of flow on $M$ explains why the addition of flood events caused Runs 2-4 to be more geomorphically active, and in particular why Run 4, that with the highest peak flow, was most active.

Many bedload transport formulae predict sediment transport as a non-linear function of some flow metric (Barry et al., 2004; DuBoys, 1879; Meyer-Peter \& Müller, 1948; Parker, 1990; Shields, 1936; Schoklitsch, 1962; Wilcock \& Kenworthy, 2002; Wilcock \& Crowe, 2003; Wong \& Parker, 2006). Eaton et al. (2020) further showed that sediment transport scales with the volume of erosion in laterally active streams. It is perhaps unsurprising then, that we observed a non-linear relation between flow rates and volumes of morphologic change. We infer that the non-linear dependence of sediment transport on flow causes this non-linearity in our data.

The sensitivity of $F_{n}$ and $M$ at high flows may also reflect the crossing of stability thresholds set by coarse grains. Experiments in a laterally mobile stream by Eaton et al. (2020) showed that as flow increased and as much as $80 \%$ of the bed material was mobilized, it was only once flows were great enough to mobilize the largest grains present that channel dimensions were modified. Consequently, they postulated that overall channel stability reflects the stability of a small population of immobile or partially mobile large grains. In a previous study analyzing Run 1 in more detail, we also observed that in-channel deposition around accumulations of the largest grains disrupted autogenic flow pattern cycling (Leenman \& Eaton, 2021). The non-linear relation between morphologic change and flow in our data may therefore indicate that channel dimensions are regulated by the (im)mobility of the coarsest grains on the fan.

Observations from this study illuminate the role that flow variability plays in controlling fan geometry, and fan gradient in particular. Different 'types' of flow variability generated different fan gradients (Figure 6): the 'flat' hydrographs in Run 2 generated steeper fans than those built by constant flow, while the 'peaked' hydrographs in Runs 3 and 4 generated the lowest fan gradients. It is difficult to interpret this pattern without accurate water-depth data with which to determine the shear stress distribution across the fan, and therefore the conditions driving entrainment and deposition. Nevertheless, Figure 12 can be used to provide insight as to whether it is flood events, or the periods of low-flow between them, that set the fan gradient.

During low-flow periods in Runs 2-4, sediment transport onto the fan slowed at the fan-head, creating a deposition zone that steepened the fan (Figure 12). Conversely, flood events eroded the fan-head and caused deposition on the lower fan which ultimately decreased fan gradient. Hooke (1968b) observed that the flow magnitude controlled the spatial location of erosion and deposition in a similar way, in an experiment with variable discharge. In our experiments, the steepening or shallowing of fan gradient that resulted from the spatial distribution of deposition is weakly evident in Figure S3 (SI), which shows how fan gradient adjusted throughout the ten-minute high-to-low flow cycle.

We speculate that the steeper gradient in Run 2 results from the relatively low peak flow of that experiment, which prevented floods from eroding the fan-head sufficiently to counterbalance the steepening in the low-flows (which were equal across Runs 2-4). Conversely, it seems that the peak flows in Runs 3 and 4 were high enough to erode the 
fan-head and redistribute sediment to the lower fan, generating low gradients. Data on the downfan distribution of shear stress are necessary to fully evaluate this hypothesis. Nevertheless, the different gradients generated by our different hydrographs demonstrate a need to incorporate multiple types of variability when modeling stream geomorphology.

The different hydrographs employed in our experiments raise the question of whether flood peak magnitude or duration has a stronger control on flood response. Field evidence offered by Costa and O'Connor (1995) and Huckleberry (1994) suggests that flood duration is more important than flood magnitude. In our study, Figure 10, which compares peak flow to cumulative morphologic change in each ten-minute flow cycle, can be used to investigate this question; however, it is possible to interpret Figure 10 to both counter and support their field observations. On one hand, Figure 10 can be interpreted to show that cumulative morphologic change scales with flood peak magnitude, an observation which contrasts the field data. Alternatively, Figure 10 can be read as supporting those authors' inferences, given that Run 2 generated larger $M_{C 10}$ values than Run 3. However, this second interpretation is weakened somewhat by the lack of a significant difference between Runs 2 and 3, and by high $M_{C 10}$ values for Run 4 . Moreover, all flood events in Runs 2-4 lasted five-minutes exactly (Figure 2), so that even though flow decayed at different rates in each hydrograph, flood duration was equal. The ambiguity of our data makes it difficult to address the 'magnitude or duration' question, and additional experiments are necessary to better compare against existing field data.

A further difficulty in comparing our experimental results to field studies is the difference in survey frequency. In the field, one can hope to capture DEMs before and after a flood; these data only allow calculation of net topographic change. It is rare to obtain topographic data at regular intervals during a flood event (as we have here), allowing to estimate the cumulative morphologic change. While the cumulative morphologic change in a ten-minute flow cycle $\left(M_{C 10}\right)$ generally scaled with the peak flow in our experiments (Figure 10), the net morphologic change was similar across all experiments (Figure S2, SI). This difference has two probable causes. Firstly, 'topographic compensation' (Lindsay \& Ashmore, 2002) between DEMs means that a DoD between the first and last DEM in a ten-minute flow cycle (used to calculate net change) fails to capture local cutting and filling at shorter time-frames. Conversely, these processes are captured in the one-minute DoDs that we summed to calculate $M_{C 10}$. Secondly, a key difference between our hydrographs was that they generated different spatial distributions of deposition (Figure 12). However, these spatial patterns are not captured in $M$ volumes. We therefore emphasize that it is necessary to compare both volumes and spatial patterns of morphologic change to understand the geomorphic impacts of the different hydrographs in our experiments.

\subsection{Implications for natural fans and their representation in models}

In our experiments, variable and constant flow produced different fan morphology, lateral mobility, and morphologic change rates, despite an equivalent mean flow across all experiments. Our results add to a growing body of evidence that variable flows play a non-negligible role in fan and fan-delta dynamics (Ganti et al., 2016; Piliouras et al., 2017; Miller et al., 2019). Using the mean flow as a constant flow (Run 1) dampened geomorphic activity and generated fans with different gradients (Figures 7, 9, and 6 respectively). These results indicate that the mean flow alone is not a suitable predictor of fan gradient nor lateral and vertical (morphologic) change.

Our experimental design demonstrates the distortions introduced through different scales of temporal averaging in the flow to fans. When we compare a temporally varying flood event (i.e. Run 3 or 4) with a constant flow flood (i.e. Run 2), the latter produced steeper fans with lower lateral migration and morphologic change. Moreover, when 
we compare our variable flow experiments (Runs 2-4) to a constant mean flow (Run 1), fan gradient was again different, and geomorphic activity was further dampened. As such, our data show that averaging out the variability in a hydrological series, across a series of flood events or even within a hydrograph, can under-represent the range of geomorphic activity that would result from those flow variations, particularly given the non-linear relations between flow and geomorphic activity.

Based on our findings, we question whether it is appropriate to use a single constant flow to represent the range of flows on natural fans. While this approach has been taken in most alluvial fan experiments that we are aware of, our results show that constant and varied flow produce different fan morphology and dynamics when the mean flow is equal. Therefore, the mean flow was not a suitable 'representative discharge' for our experimental fans - neither for replicating fan gradient, nor for lateral mobility and sediment movement volumes.

Hooke and Rohrer (1979) attempted to determine a representative discharge on alluvial fans. Rather than the bankfull flood, they defined the representative discharge as the single constant flow that built fans with a gradient equal to that of fans built with a range of flows. Their experiments indicated that the representative discharge was somewhere been the 64th and 75th percentile of flows. However, even if one can use a 'representative' constant flow to recreate fan gradient, our data showed that morphologic change was non-linearly related to the flow. Consequently, if we had used a constant flow equal to the 70th percentile of our variable flows (following Hooke and Rohrer (1979)), Figures 9-11 suggest that we would likely have built fans with lower maximum and cumulative reworking rates than in our widely-varying flow experiments. Even if we replicated fan gradient using a constant flow, we would still fail to represent the range of morphologic change and lateral mobility rates, and therefore, the hazard regime, on a fan subject to variable flows. We thus suggest that the choice to represent a range of flows with a single representative flow in alluvial fan studies must depend on the research question or hazard management problem at hand.

\section{Conclusion}

We conducted four alluvial fan experiments to examine the role that flow variability plays in fan morphodynamics. We compared one experiment with constant flow to three with temporally varying flow (each with a series of repeated flood hydrographs: one experiment had flat hydrographs, one had moderate flood peaks that decayed slowly, and one had higher flood peaks that decayed rapidly). Mean flow and sediment supply were constant and equal across all experiments. The four experiments generated different fan gradients, lateral mobility rates and morphologic change (erosion and deposition): greater morphologic change and lower gradients were associated with greater flood peaks. Moreover, the type of flow variability was important: flat and decaying hydrographs with the same total flood volume had different effects.

The instantaneous flow rate was a key control on lateral mobility and morphologic change. The maximum flow in a given minute (a proxy for the instantaneous flow) was related non-linearly to lateral channel mobility and the morphologic change rate; both increased faster than linearly as the flow increased. This non-linearity meant that as the peak flow increased across our three hydrograph shapes, lateral mobility and morphologic change achieved considerably higher maxima.

These results demonstrate that temporally averaged flow metrics, such as the mean flow, mean flood flow or total flood volume, are not suitable predictors of fan morphology (i.e gradient) or flood impacts. Applying such metrics to our results would lead us to underestimate the maximum lateral mobility and morphologic change rates, or wrongly predict fan gradient. We therefore question the use of a 'representative' flow in alluvial 
fan experiments and simulations. The choice of a representative flow, when one must be used, will depend on the aspect of fan morphology or dynamics that is of interest.

Finally, our experiments shed light on how changes to flood hydrograph shape on natural fans could influence fan responses to flood events. Flood hydrograph shape in an alluvial fan catchment may change over time, in response to land cover change or flow regulation. By modeling fan responses to different flood hydrographs, we advance understanding of how hydrograph shape can impact streams on alluvial fans and their responses to flood events.

\section{Acknowledgments}

A. Leenman was funded by a UBC Four-Year Fellowship. Experimental construction was funded through an NSERC Discovery Grant to B. Eaton. Thanks to Mike Church and Lauren Vincent for helpful comments and discussions which greatly improved the quality and clarity of our manuscript.

The data underlying all figures in this manuscript are available from the Canadian Federated Research Data Repository (FRDR) at https://doi.org/10.20383/102.0482. 


\section{References}

Agisoft photoscan professional. (2018, Dec).

(Structure-from-Motion photogrammetry software, accessed via https://www.agisoft.com/downloads/installer/)

Ashworth, P. J., Best, J. L., Leddy, J. O., \& Geehan, G. W. (1994). The physical modelling of braided rivers and deposition of fine-grained sediment. In M. J. Kirkby (Ed.), Process models and theoretical geomorphology (pp. 115139). John Wiley and Sons.

Barry, J. J., Buffington, J. M., \& King, J. G. (2004). A general power equation for predicting bed load transport rates in gravel bed rivers. Water Resources Research, 40(10). doi: https://doi.org/10.1029/2004WR003190

Beaumont, P., \& Oberlander, T. (1971). Observations on stream discharge and competence at Mosaic Canyon, Death Valley, California. Geological Society of America Bulletin, 82(6), 1695-1698.

Blair, T. C., \& McPherson, J. G. (1994). Alluvial fans and their natural distinction from rivers based on morphology, hydraulic processes, sedimentary processes, and facies assemblages. Journal of sedimentary research, 64(3a), 450-489.

Bryant, M., Falk, P., \& Paola, C. (1995). Experimental study of avulsion frequency and rate of deposition. Geology, 23(4), 365-368. doi: 10.1130/0091-7613(1995) 023<0365:ESOAFA $>2.3 . \mathrm{CO}$

Church, M., \& Ferguson, R. (2015). Morphodynamics: Rivers beyond steady state. Water Resources Research, 51 (4), 1883-1897.

Church, M., \& Jakob, M. (2020). What is a debris flood? Water resources research, $56(8)$, e2020WR027144.

Clarke, L., Quine, T. A., \& Nicholas, A. (2010). An experimental investigation of autogenic behaviour during alluvial fan evolution. Geomorphology, 115(3), 278-285.

Costa, J. E., \& O'Connor, J. E. (1995). Geomorphically effective floods. In J. Costa, A. Miller, K. Potter, \& P. Wilcock (Eds.), Natural and anthropogenic influences in fluvial geomorphology (p. 45-56). American Geophysical Union (AGU) Monograph 89. doi: https://doi.org/10.1029/GM089p0045

Davidson, S. K., Hartley, A. J., Weissmann, G. S., Nichols, G. J., \& Scuderi, L. A. (2013). Geomorphic elements on modern distributive fluvial systems. Geomorphology, 180-181, 82 - 95. doi: https://doi.org/10.1016/ j.geomorph.2012.09.008

Davidson, S. L., \& Eaton, B. C. (2018). Beyond regime: A stochastic model of floods, bank erosion, and channel migration. Water Resources Research, 54 (9), $6282-6298$.

Davies, T. R., \& Korup, O. (2007). Persistent alluvial fanhead trenching resulting from large, infrequent sediment inputs. Earth Surface Processes and Landforms, 32(5), 725-742.

Davies, T. R., McSaveney, M. J., \& Clarkson, P. J. (2003). Anthropic aggradation of the Waiho River, Westland, New Zealand: microscale modelling. Earth Surface Processes and Landforms, 28(2), 209-218.

De Haas, T., Kruijt, A., \& Densmore, A. (2018). Effects of debris-flow magnitudefrequency distribution on avulsions and fan development. Earth Surface Processes and Landforms, 43(13), 2779-2793.

De Haas, T., Van Den Berg, W., Braat, L., \& Kleinhans, M. G. (2016). Autogenic avulsion, channelization and backfilling dynamics of debris-flow fans. Sedimentology, 63(6), 1596-1619.

Delorme, P., Devauchelle, O., Barrier, L., \& Métivier, F. (2018). Growth and shape of a laboratory alluvial fan. Physical Review E, 98(1), 012907.

Delorme, P., Voller, V., Paola, C., Devauchelle, O., Lajeunesse, É., Barrier, L., \& Métivier, F. (2017). Self-similar growth of a bimodal laboratory fan. Earth Surface Dynamics, 5(2), 239 - 252. doi: 10.5194/esurf-5-239-2017 
DuBoys, M. (1879). Etudes du regime et l'action exercée par les eaux sur un lit a fond de graviers indefinement affouilable. Annals des Ponts et Chaussées, 5 , $141-195$.

Eaton, B. C. (2013). Hydraulic Geometry: Empirical Investigations and Theoretical Approaches. $\quad$ In E. W. John F. Shroder (Ed.), Treatise on geomorphology (Vol. 9 (Fluvial Geomorphology), p. 313-329). San Diego: Academic Press. doi: https://doi.org/10.1016/B978-0-12-374739-6.00243-8

Eaton, B. C., MacKenzie, L. G., \& Booker, W. H. (2020). Channel stability in steep gravel-cobble streams is controlled by the coarse tail of the bed material distribution. Earth Surface Processes and Landforms, 45(14), 3639-3652. doi: https://doi.org/10.1002/esp.4994

Field, J. (2001). Channel avulsion on alluvial fans in southern Arizona. Geomorphology, $37(1-2), 93-104$.

Ganti, V., Chadwick, A. J., Hassenruck-Gudipati, H. J., Fuller, B. M., \& Lamb, M. P. (2016). Experimental river delta size set by multiple floods and backwater hydrodynamics. Science advances, 2(5), e1501768.

Guerit, L., Métivier, F., Devauchelle, O., Lajeunesse, É., \& Barrier, L. (2014). Laboratory alluvial fans in one dimension. Physical Review E, 90(2), 022203.

Gutiérrez, F., Gutiérrez, M., \& Sancho, C. (1998). Geomorphological and sedimentological analysis of a catastrophic flash flood in the Arás drainage basin (Central Pyrenees, Spain). Geomorphology, 22(3-4), 265-283.

Hamilton, P. B., Strom, K., \& Hoyal, D. C. (2013). Autogenic incision-backfilling cycles and lobe formation during the growth of alluvial fans with supercritical distributaries. Sedimentology, 60(6), 1498-1525.

Hijmans, R. J. (2020). raster: Geographic data analysis and modeling [Computer software manual]. Retrieved from https://CRAN.R-project.org/ package=raster ( $\mathrm{R}$ package version 3.4-5)

Hooke, R. L. (1967). Processes on arid-region alluvial fans. The Journal of Geology, $75(4), 438-460$.

Hooke, R. L. (1968a). Model geology: prototype and laboratory streams: discussion. Geological Society of America Bulletin, 79(3), 391-394.

Hooke, R. L. (1968b). Steady-state relationships on arid-region alluvial fans in closed basins. American Journal of Science, 266 (8), 609-629.

Hooke, R. L., \& Rohrer, W. L. (1979). Geometry of alluvial fans: Effect of discharge and sediment size. Earth Surface Processes, 4(2), 147-166. doi: 10.1002/esp .3290040205

Huckleberry, G. $\quad(1994,12)$. Contrasting channel response to floods on the middle Gila River, Arizona. Geology, 22(12), 1083-1086. doi: 10.1130/0091-7613(1994) 022 $\langle$ 1083:CCRTFO $\rangle$ 2.3.CO;2

Jakob, M., Clague, J. J., \& Church, M. (2016). Rare and dangerous: Recognizing extra-ordinary events in stream channels. Canadian Water Resources Journal/Revue canadienne des ressources hydriques, 41(1-2), 161-173.

Jakob, M., Weatherly, H., Bale, S., Perkins, A., \& MacDonald, B. (2017). A MultiFaceted Debris-Flood Hazard Assessment for Cougar Creek, Alberta, Canada. Hydrology, 4(1), 7.

Kassambara, A. (2020). rstatix: Pipe-friendly framework for basic statistical tests [Computer software manual]. Retrieved from https://CRAN.R-project.org/ package=rstatix $(\mathrm{R}$ package version 0.5 .0$)$

Kesel, R. H., \& Lowe, D. R. (1987). Geomorphology and sedimentology of the Toro Amarillo alluvial fan in a humid tropical environment, Costa Rica. Geografiska Annaler: Series A, Physical Geography, 69(1), 85-99.

Larsen, M. C., Wieczorek, G. F., Eaton, L., \& Torres-Sierra, H. (2001). Natural hazards on alluvial fans: the debris flow and flash flood disaster of December 1999, Vargas state, Venezuela. In W. Sylva (Ed.), Proceedings of the sixth caribbean islands water resources congress (Vol. 965, pp. 1-7). Mayagüez, 
Puerto Rico.

Leenman, A. (2021). Environmental variability and geomorphic responses on alluvial fans: An experimental study (Unpublished doctoral dissertation). University of British Columbia, Vancouver, Canada.

Leenman, A., \& Eaton, B. C. (2021). Mechanisms for avulsion on alluvial fans: insights from high-frequency topographic data. Earth Surface Processes and Landforms, 46(6), 1111-1127. doi: 10.1002/esp.5059.

Lindsay, J. B., \& Ashmore, P. E. (2002). The effects of survey frequency on estimates of scour and fill in a braided river model. Earth Surface Processes and Landforms, 27(1), 27-43. doi: https://doi.org/10.1002/esp.282

Meyer-Peter, E., \& Müller, R. (1948). Formulas for bed-load transport. In Iahsr 2nd meeting, stockholm, appendix 2.

Miller, K. L., Kim, W., \& McElroy, B. (2019). Laboratory Investigation on Effects of Flood Intermittency on Fan Delta Dynamics. Journal of Geophysical Research: Earth Surface, 124(2), 383-399.

Paola, C., Straub, K., Mohrig, D., \& Reinhardt, L. (2009). The "unreasonable effectiveness" of stratigraphic and geomorphic experiments. Earth-Science Reviews, 97(1-4), 1-43.

Parker, G. (1979). Hydraulic geometry of active gravel rivers. Journal of the Hydraulics Division, 105(9), 1185-1201. doi: 10.1061/JYCEAJ.0005275

Parker, G. (1990). Surface-based bedload transport relation for gravel rivers. Journal of hydraulic research, 28(4), 417-436.

Peakall, J., Ashworth, P., \& Best, J. (1996, January 1). Physical modelling in fluvial geomorphology: principles, applications and unresolved issues. In The scientific nature of geomorphology: Proceedings of the 27th binghamton symposium in geomorphology (pp. 221-253). John Wiley and Sons.

Pearthree, P. A., Klawon, J. E., \& Lehman, T. W. (2004). Geomorphology and hydrology of an alluvial fan flood on Tiger Wash, Maricopa and La Paz Counties, west-central Arizona (Tech. Rep. No. 04-02). Arizona Geological Survey.

Piliouras, A., Kim, W., \& Carlson, B. (2017). Balancing aggradation and progradation on a vegetated delta: The importance of fluctuating discharge in depositional systems. Journal of Geophysical Research: Earth Surface, 122(10), $1882-1900$.

R Core Team. (2021). R: A language and environment for statistical computing [Computer software manual]. Vienna, Austria. Retrieved from https://www.R -project.org/

Rahn, P. H. (1967). Sheetfloods, streamfloods, and the formation of pediments. Annals of the Association of American Geographers, 57(3), 593-604.

Reitz, M. D., \& Jerolmack, D. J. (2012). Experimental alluvial fan evolution: Channel dynamics, slope controls, and shoreline growth. Journal of Geophysical Research: Earth Surface, 117(F2), F02021.

Reitz, M. D., Jerolmack, D. J., \& Swenson, J. B. (2010). Flooding and flow path selection on alluvial fans and deltas. Geophysical Research Letters, 37(6), L06401. doi: 10.1029/2009GL041985

Santo, A., Santangelo, N., Di Crescenzo, G., Scorpio, V., De Falco, M., \& Chirico, G. B. (2015). Flash flood occurrence and magnitude assessment in an alluvial fan context: the October 2011 event in the Southern Apennines. Natural Hazards, 78(1), 417-442.

Schlichting, H., \& Gersten, K. (2016). Boundary-layer theory. Springer.

Schoklitsch, A. (1962). Handbuch des wasserbaues (3rd ed.). Vienna: Springer.

Schumm, S. A., Mosley, M. P., \& Weaver, W. (1987). Experimental fluvial geomorphology. New York: John Wiley and Sons Inc.

Shields, A. (1936). Anwendung der aehnlichkeitsmechanik und der turbulenzforschung auf die geschiebebewegung (Unpublished doctoral dissertation). Technical University Berlin. 
Van Dijk, M., Kleinhans, M. G., Postma, G., \& Kraal, E. ～(2012). Contrasting morphodynamics in alluvial fans and fan deltas: effect of the downstream boundary. Sedimentology, 59(7), 2125-2145.

Van Dijk, M., Postma, G., \& Kleinhans, M. G. (2009). Autocyclic behaviour of fan deltas: an analogue experimental study. Sedimentology, 56(5), 1569-1589.

Vincent, L. (2020). The Importance of Secondary Processes on Alluvial Fan Morphology, Behaviour, and Hazards (Unpublished master's thesis). University of British Columbia, Vancouver, Canada.

Whipple, K. X., Parker, G., Paola, C., \& Mohrig, D. (1998). Channel dynamics, sediment transport, and the slope of alluvial fans: Experimental study. Journal of Geology, 106(6), 677-693.

Wilcock, P. R., \& Crowe, J. C. (2003). Surface-based transport model for mixed-size sediment. Journal of Hydraulic Engineering, 129(2), 120-128.

Wilcock, P. R., \& Kenworthy, S. T. (2002). A two-fraction model for the transport of sand/gravel mixtures. Water Resources Research, 38(10), 12-1.

Wong, M., \& Parker, G. (2006). Reanalysis and correction of bed-load relation of Meyer-Peter and Müller using their own database. Journal of Hydraulic Engineering, 132(11), 1159-1168.

Woods, S. W., MacDonald, L. H., \& Westbrook, C. J. $\quad$ (2006). Hydrologic interactions between an alluvial fan and a slope wetland in the central Rocky Mountains, USA. Wetlands, 26(1), 230-243.

Yalin, M. S. (1971). Theory of hydraulic models. Macmillan International Higher Education.

Yumuang, S. (2006). 2001 debris flow and debris flood in Nam Ko area, Phetchabun province, central Thailand. Environmental Geology, 51(4), 545-564. 


\title{
Supporting information for 'Floods on alluvial fans: implications for reworking rates, morphology and fan hazards'
}

\author{
A. S. Leenman ${ }^{1}$, B. C. Eaton ${ }^{1}$, and L. G. MacKenzie ${ }^{2}$ \\ ${ }^{1}$ Department of Geography, University of British Columbia, Vancouver BC, Canada \\ ${ }^{2}$ Department of Forest Resources Management, University of British Columbia, Vancouver BC, Canada
}

\section{Analysis details}

\subsection{Flow map generation}

We generated flow maps from the $1 \mathrm{~mm}$ orthophotos for each minute of the experiment. We added blue dye to the water in the experiment, so flow had a strong signal in each color band in the orthophoto: a high reflectance in the blue and green bands, and a low reflectance in the red band. Based on this signal, we created a color index to further emphasize the flow, calculated as follows:

$$
\text { color index }=\frac{\text { blue }+ \text { green }- \text { red }}{\text { blue }+ \text { green }+ \text { red }}
$$

We calculated the color index for each cell, and then normalized the value by the total reflectance for that cell (as in Equation 1), thereby accounting for spatial variations in lighting. We then set a threshold for each image, of $5 \%$ above the mean color index calculated over that image. This movable threshold was necessary because the concentration of blue dye varied between experiments (due to evaporation, and the need to periodically clean and refill the water supply tanks), preventing the use of a single threshold value to isolate wet areas. Cells where the threshold was exceeded were isolated as 'wet' (i.e. flow). We then removed patches smaller than $10 \mathrm{~cm}^{2}$, and smoothed the flow maps with a $21 \times 21$ cell majority filter to create smooth flow boundaries that better matched our visual interpretation of the flow location.

Corresponding author: Anya Leenman, anya.leenman@alumni.ubc.ca 


\section{Results}

Table 1. Results of pairwise t-tests between the median slope populations for different runs in Figure M6a (main manuscript). P-values were calculated using the rstatix package ('Bonferonni' method for p-value adjustment; see Kassambara (2020) for details). Although slope was measured at 1-minute intervals, sequential observations were temporally autocorrelated, violating the assumption of independence within each experimental repeat (although fan slope during each experimental repeat was independent of that during other experimental repeats). To reduce the effects of temporal autocorrelation, slope data were sampled at 15 minute intervals within each experimental repeat (although this did not completely remove the autocorrelation within each experiment). Sample sizes were 86-87.

\begin{tabular}{cccc} 
Run & vs Run & p-value & Adjusted p-value \\
\hline 1 & 2 & $8.21 \times 10^{-5}$ & $4.92 \times 10^{-4}$ \\
1 & 3 & $8.96 \times 10^{-11}$ & $5.38 \times 10^{-10}$ \\
1 & 4 & $4.24 \times 10^{-13}$ & $2.54 \times 10^{-12}$ \\
2 & 3 & $2.78 \times 10^{-23}$ & $1.67 \times 10^{-22}$ \\
2 & 4 & $2.52 \times 10^{-26}$ & $1.51 \times 10^{-25}$ \\
3 & 4 & 0.396 & 1.00 \\
\hline
\end{tabular}

Table 2. Model fit parameters for different models fitted to Figure M8. The power-law relation fit the data best. Mean squared error (MSE) is calculated as $\frac{1}{n-2} \sum_{i=1}^{n}\left(y_{i}-\hat{y}_{i}\right)^{2}$. Residual error is calculated as $\sqrt{M S E}$.

\begin{tabular}{lcc} 
Type & Mean Squared Error & Residual Error \\
\hline Power-law & 2.895 & 1.701 \\
Quadratic & 2.897 & 1.702 \\
Exponential & 3.068 & 1.752 \\
Linear & 3.159 & 1.777 \\
\hline
\end{tabular}


Table 3. Results of pairwise t-tests between the cumulative volumetric change populations for different runs in Figure M10. P-values were calculated using the rstatix package ('Bonferonni' method for p-value adjustment; see Kassambara (2020) for details). Sample sizes were 144-195. Runs 2 and 3 were not significantly different.

\begin{tabular}{cccc} 
Run & vs Run & p-value & Adjusted p-value \\
\hline 1 & 2 & $1.22 \times 10^{-14}$ & $7.33 \times 10^{-14}$ \\
1 & 3 & $5.85 \times 10^{-8}$ & $3.51 \times 10^{-7}$ \\
1 & 4 & $1.22 \times 10^{-23}$ & $7.29 \times 10^{-23}$ \\
2 & 3 & $1.73 \times 10^{-2}$ & $1.04 \times 10^{-1}$ \\
2 & 4 & $4.11 \times 10^{-3}$ & $2.46 \times 10^{-2}$ \\
3 & 4 & $3.66 \times 10^{-7}$ & $2.19 \times 10^{-6}$ \\
\hline
\end{tabular}
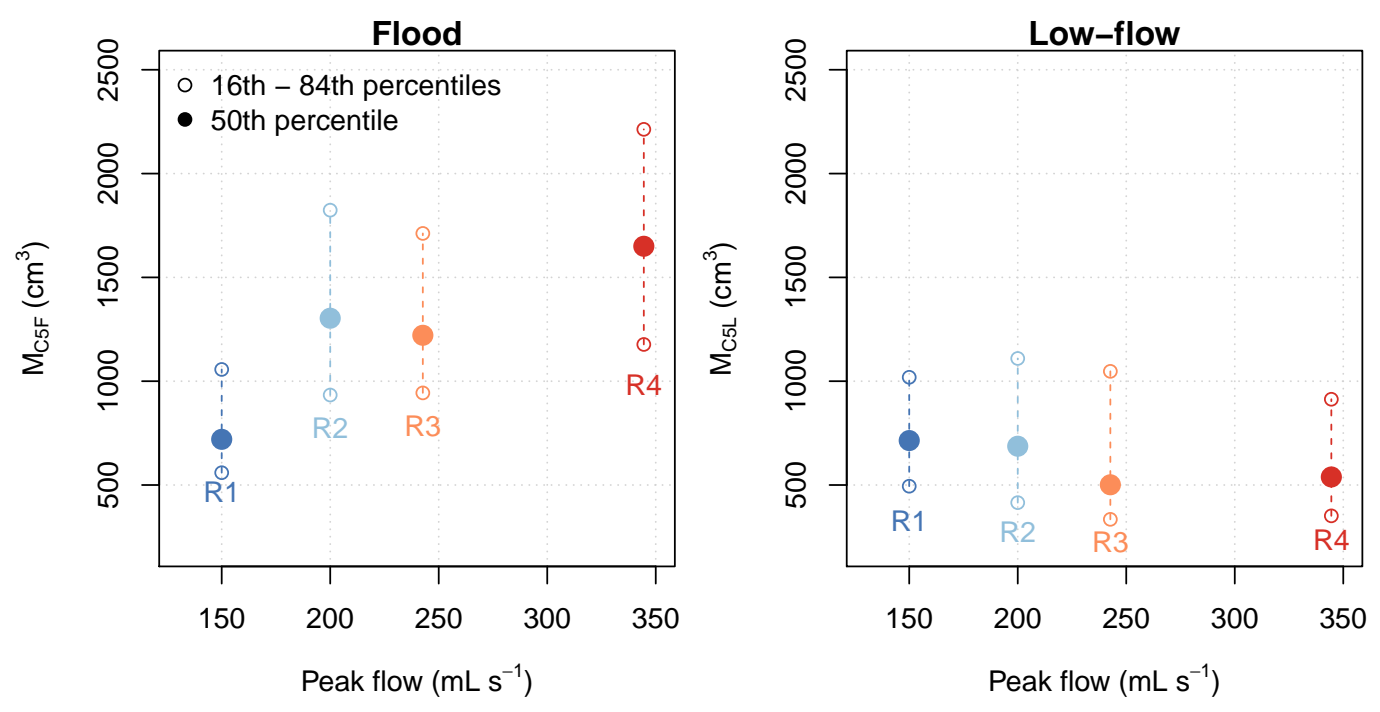

Figure 1. Cumulative morphologic change in the five-minute floods $\left(M_{C 5 F}\right.$, left) and lowflows $\left(M_{C 5 L}\right.$, right). During flood events, cumulative morphologic change scaled approximately with the peak flood flow, following Figure M10 in the main manuscript. Conversely, hydrograph shape during the floods had a negligible effect on cumulative morphologic change in the intervening low-flow periods.

Table 4. Results of pairwise t-tests between the net volumetric change populations for different runs in Figure S2. P-values were calculated using the rstatix package ('Bonferonni' method for p-value adjustment; see Kassambara (2020) for details). Sample sizes were 145-195. Only Runs 1 and 4 were significantly different.

\begin{tabular}{cccc} 
Run & vs Run & p-value & Adjusted p-value \\
\hline 1 & 2 & 0.0198 & 0.119 \\
1 & 3 & 0.0175 & 0.105 \\
1 & 4 & 0.0000324 & 0.000194 \\
2 & 3 & 0.911 & 1 \\
2 & 4 & 0.0413 & 0.248 \\
3 & 4 & 0.0607 & 0.364 \\
\hline
\end{tabular}




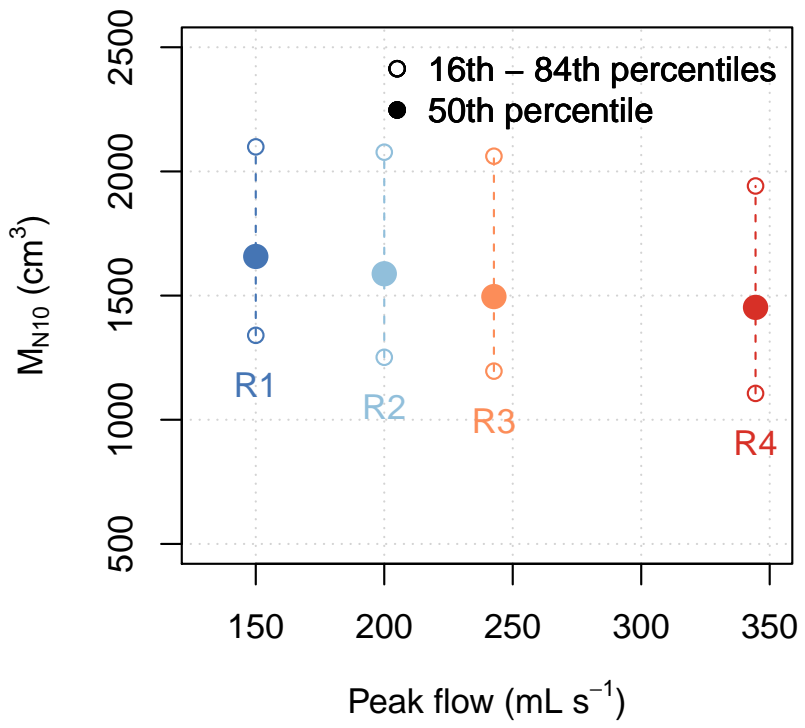

Figure 2. Net morphologic change in the ten-minute high-to-low flow cycle, for the different runs. DEMs 10 minutes apart were subtracted to generate a DoD (i.e. t10-t0); absolute aggradation and degradation values were then summed to give $M_{N 10} . M_{N 10}$ was not significantly different between runs, apart from between Runs 1 and 4 (see Table S4).

Table 5. Model fit parameters for different models fitted to Figure M11. The quadratic and power-law relations fit the data best, although the power-law is more physically realistic. Mean squared error (MSE) is calculated as $\frac{1}{n-2} \sum_{i=1}^{n}\left(y_{i}-\hat{y}_{i}\right)^{2}$. Residual error is calculated as $\sqrt{M S E}$.

\begin{tabular}{lcc} 
Type & Mean Squared Error & Residual Error \\
\hline Power-law & 108920 & 330.04 \\
Quadratic & 108900 & 330.00 \\
Exponential & 111020 & 333.20 \\
Linear & 110430 & 332.31
\end{tabular}
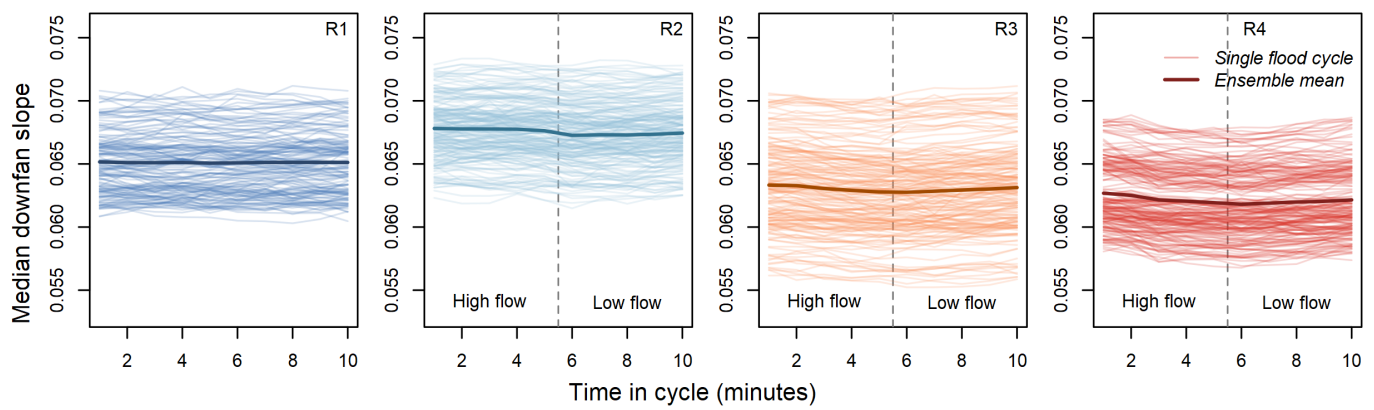

Figure 3. Changes in the median fan slope throughout the ten-minute high-to-low flow cycle, in each experimental run. In runs 3 and 4, the changes are most easily distinguishable: the fan steepened during low-flow periods, and flattened during flood events. 


\section{${ }_{25} \quad$ References}

26

27

28

Kassambara, A. (2020). rstatix: Pipe-friendly framework for basic statistical tests [Computer software manual]. Retrieved from https://CRAN.R-project.org/ package=rstatix $(\mathrm{R}$ package version 0.5 .0$)$ 